\title{
Hermann Helmholtz from A to Z
}

Kragh, Helge Stjernholm

Published in:

Metascience

DOI:

10.1007/s11016-019-00455-5

Publication date:

2019

Document version

Publisher's PDF, also known as Version of record

Document license:

CC BY

Citation for published version (APA):

Kragh, H. S. (2019). Hermann Helmholtz from A to Z. Metascience, 1-3. https://doi.org/10.1007/s11016-01900455-5 


\section{Hermann Helmholtz from A to Z}

\section{David Cahan: Helmholtz: A life in science. Chicago and London: University of Chicago Press, 2018, viii + 937 pp, \$55 HB}

\section{Helge Kragh ${ }^{1}$}

(c) Springer Nature B.V. 2019

After being ennobled in 1883, Hermann Helmholtz became Hermann von Helmholtz. Whether with or without the "von", he was and still is recognized as a giant of nineteenth-century physiology and physics and an iconic figure in German science and culture generally. And yet, despite his elevated status in the history of science, until the 1980s relatively little scholarly work was devoted to Helmholtz, his work and his influence. The somewhat hagiographic standard biography by the mathematician Leo Koenigsberger was published nearly 120 years ago and is long outdated. Of course, the subject of David Cahan's biography is the same as Koenigsberger's, but this is about the only similarity.

Cahan's comprehensive study of Helmholtz is critical and balanced, and it deals in fascinating details with just about every aspect related to Helmholtz's life and work, scientific as well as nonscientific. Insofar as the book has a focus, it is on Helmholtz as a representative of German culture during a period in which science was increasingly recognized as a national resource. As Cahan writes, his work is a biography in the broadest sense of the term, "a cultural and not a narrowly scientific biography" (5). A biography of a scientist does not have to be "narrowly scientific" as it can describe the portrayed scientist's work comprehensively without engaging in technical details. This is what Cahan does, not only when it comes to Helmholtz's seminal contributions to physics and physiology but also in other and less wellknown areas such as chemistry, psychology and mathematics.

Helmholtz's scientific interests and activities covered a very broad range, including not only original works in science but also teaching, popular writings and institutional settings. All this is fully described in Cahan's biography, which weaves together into a whole Helmholtz's contributions to and impact on science broadly conceived. Cahan's biography is not simply about a glorious career in science and culture, for Cahan also includes detailed sections on Helmholtz's private life, his happy marriages (first to Olga and next to Anna), his extensive networking activities

Helge Kragh

helge.kragh@nbi.ku.dk

1 Copenhagen, Denmark 
and his numerous travels. He made his first trip to Britain in 1853 and travelled as far as North Africa and the USA, the latter journey to participate in the International Electrical Congress held in Chicago in 1893. Helmholtz's many later visits to Britain were important because of the close relations he established with British scientists, such as William Thomson and James Clerk Maxwell. He did more than any other individual to break down the scientific barriers between Britain and Germany.

This massive book is the culmination of Cahan's long-time research programme, which, since the mid-1980s, has resulted in a series of valuable papers and books. Helmholtz is in many ways a traditional biography based extensively on a wealth of letters and other archival sources. Although it goes far beyond the Victorian lifeand-letters genre by its critical and contextual approach, it also has elements in common with this classical genre. The chronological birth-to-death structure is fairly conventional. Cahan's book is structured in three large parts, starting with Helmholtz's childhood and youth in Potsdam and ending with his position in Berlin as a celebrated Kulturträger and doyen of German science. The section with notes and references at the end of the book takes up more than 140 pages, an indication of how meticulously researched the book is. In my view, it would have been helpful if the author had included a timeline summarizing the most important events in Helmholtz's life and career. Readers easily get lost in the huge amount of data and information that fills the book.

Despite his status as one of the giants of nineteenth-century science, Helmholtz is not generally considered a genius on a par with, for example, Gauss and Einstein. And yet he was a genius in the sense of the famous American inventor Thomas Edison, who allegedly defined genius as $99 \%$ perspiration and $1 \%$ inspiration. Incidentally, Helmholtz was acquainted with Edison, whom he met in Paris in 1889 and again in Chicago and New York four years later. Throughout his life, Helmholtz worked extremely hard, which to a large extent was the secret behind his successful career. Cahan speaks of his "enormously strong work ethics" (321), which he traces to the influence of his father and early school education.

While some historians of science will primarily associate Helmholtz with his work in physiology, others will pay more attention to his work in various branches of physics. Of course, from a biographical perspective, the distinction is artificial and Cahan covers both areas_-indeed all of Helmholtz's scientific publications. In the first part of the book, physiology is in focus with much emphasis given to Helmholtz's invention of the ophthalmoscope in 1851 and his two influential monographs Tonempfindungen (1863) and Handbuch der physiologischen Optik (1867). While these works and their impact are described in great detail, Helmholtz's earlier and most important work on energy conservation, his Ueber die Erhaltung der Kraft from 1847, is not analysed to the same extent. There is much about its origin, context and reception but surprisingly little about its content.

Cahan's decision to write a contextual biography of a scientist rather than a scientific biography is praiseworthy but not without problems. It implies that relatively little attention is given to technical and scientific content even when this is of crucial importance to the work under consideration. For example, Cahan describes in interesting detail Helmholtz's work on the foundation of geometry and the new ideas of nonEuclidean geometry in which he was a pioneer. In my view, the section would have been more clear and informative if a few technicalities and simple equations had been 
included. The same goes for the sections in which Cahan describes Helmholtz's important contributions to hydrodynamics, electrodynamics, and chemical thermodynamics. In the latter case, we are given a fine qualitative and nontechnical account of his contributions to the emergence of physical chemistry, including the so-called Helmholtz equation and the free energy, now generally known as the Helmholtz free energy. But it does not appear very clearly what the free energy is, and the chemical equation named after Helmholtz remains just a name.

More generally, while Cahan's biography is of great interest to historians of science and culture, it is unlikely to appeal to scientists. As far as philosophers are concerned, they may be disappointed to learn that Helmholtz was rather sceptical about the role of philosophy in science and only admitted epistemology as deriving from science and not preceding it. He generally dismissed metaphysics and had no close relations to the German philosophical community. In a letter to the physiologist Carl Ludwig of 1869, he wrote: "I find that too much philosophizing ultimately leads to a certain demoralization and vagueness" (533). As to the much-discussed question of whether Helmholtz was a Kantian or not, Cahan argues that this was only the case in a very limited sense and that his Kantianism was restricted to Kant's epistemological views.

Among the strengths of Cahan's biography is that it provides a vivid, authentic and most detailed picture of Helmholtz, his personality, his science and his era in general. All of his many meetings, travels and awards are carefully described, including all, or nearly all, of the large number of people he met and had contact with. The details based on the rich collection of sources are almost too many, and at times, they make it difficult to see the forest for all the trees. I feel that the work does not sufficiently distinguish between what is important and not so important. For example, Cahan deals at length with Helmholtz's writings on music, art and aesthetics, and also with his view on Goethe. These subjects belonged to the interests of the versatile Helmholtz, but I am not convinced that they were of great importance compared to his scientific contributions.

I have only spotted a few errors or inaccuracies, one of them concerning the Leipzig astrophysicist Karl Friedrich Zöllner, who was an enemy of Helmholtz and is described as an antimodernist critic of non-Euclidean geometry (on 495). Zöllner was in fact the first to apply Riemann's version of non-Euclidean geometry to the stellar universe. With regard to Heinrich Hertz's discovery of the photoelectric effect, it is said (on 608) that it was not fully appreciated until Einstein's quantum-based explanation of 1905. This is a mistake or at least a gross overstatement.

Although Cahan's biography can be criticized on some points, it is without a doubt a masterpiece, which comes close to a definitive study of the great scientist. It does for Helmholtz what Crosbie Smith and Norton Wise did in 1989 for William Thomson in their pioneering study Energy \& Empire. Cahan's book is a must read for scholars of Helmholtz and nineteenth-century German science and culture. It is also warmly recommended to a more general readership.

Publisher's Note Springer Nature remains neutral with regard to jurisdictional claims in published maps and institutional affiliations. 